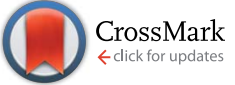

Cite this: RSC Adv., 2017, 7, 7250
Received 12th December 2016 Accepted 12th January 2017

DOI: 10.1039/c6ra28067f

www.rsc.org/advances

\section{Sulfonated multi-walled carbon nanotubes for biodiesel production through triglycerides transesterification}

\author{
Qingqing Guan, ${ }^{a}$ Yi Li, ${ }^{a}$ Yuan Chen, ${ }^{\mathrm{b}}$ Yuzhen Shi, ${ }^{\mathrm{a}} \mathrm{Junjie} \mathrm{Gu},{ }^{\mathrm{a}}$ Bin Li, ${ }^{\mathrm{a}}$ Rongrong Miao, ${ }^{\mathrm{a}}$ \\ Qiuling Chen ${ }^{a}$ and Ping Ning*a
}

\begin{abstract}
Effective solid acid catalysts play a key role to produce high-quality biodiesel through triglyceride transesterification. The present work describes a facile technique for the synthesis of a high-performing sulfonated multi-walled carbon nanotube (S-MWCNTs) solid acid catalyst for fatty acid ethyl ester (biodiesel) production. The results indicated that S-MWCNTs possessed high acidity due to their polycyclic textural matrix. An overall conversion of $97.8 \%$ is achieved for triglycerides at $1 \mathrm{~h}, 150{ }^{\circ} \mathrm{C}$ using $3.7 \mathrm{wt} \%$ of catalyst in ethanol, outperforming its counterpart catalysts, such as hydrothermal carbonization synthesized sulfonated carbon and metal oxide catalyst $\mathrm{WO}_{3} / \mathrm{ZrO}_{2}$. This superior performance is a result of the high acidity that S-MWCNTs possess, stemming from their polycyclic textural matrix. The catalyst was fully characterized by BET, FT-IR, XPS and TEM measurements to understand and evaluate their physical and structural properties. Combining activity and characterization data enables the postulation of the following reaction mechanisms for triglyceride transesterification based on S-MWCNTs: $\mathrm{SO}_{3} \mathrm{H}$ groups first absorb triglycerides and ethanol through the interaction between the acid sites and the atomic oxygen. The carbonyl carbon was then attacked by the nucleophilic ethanol to produce fatty acidethyl ester $\left(\mathrm{CH}_{3} \mathrm{CH}_{2} \mathrm{COOR}\right)$, the final product. Findings from this work provide useful insights on designing effective solid acid catalysts via facile synthesis and regeneration protocol for the transesterification of triglyceride to produce biodiesels.
\end{abstract}

\section{Introduction}

The depletion of fossil fuels in the near future and the growing environmental concern over greenhouse gas emission encourage the development of alternative and sustainable fuels. ${ }^{1,2}$ Biodiesel (BD), typically derived from vegetable and animal oils, or other renewable raw materials, presents a promising solution. It has already been successfully used as commercial fuel for diesel engines with moderate modification. ${ }^{3}$

The two conventional ways for BD production are free fatty acid (FFA) esterification and triglyceride (TG) transesterification. ${ }^{4}$ The transesterification process is utilized more commonly, where alcohols react with triglyceride, di-glycerides and mono-glycerides to produce fatty acid alkyl esters (FAAE) and glycerol. ${ }^{5}$ Typically, catalysts such as acid/base catalysts, ${ }^{6,7}$ and enzymatic catalysts, ${ }^{8}$ as well as microwave heating, ${ }^{9}$ supercritical treatment, ${ }^{10}$ and ultrasonic irradiation ${ }^{\mathbf{1 1}}$ are used to catalyze or facilitate the transesterification reactions. Base

${ }^{a}$ Collaborative Innovation Center of Western Typical Industry Environmental Pollution Control, Faculty of Environmental Science and Engineering, Kunming University of Science and Technology, Kunming 650500, China. E-mail: ningping1958@163.com ${ }^{b}$ Institute for Integrated Catalysis, Pacific Northwest National Laboratory, Richland, WA 99354, USA catalysts, such as $\mathrm{NaOH}, \mathrm{KOH}$, and $\mathrm{NaOMe}$, are among the most common catalysts selected for this process, due to their abundancy, low-cost and high efficiency under moderate conditions. ${ }^{5,12}$ However, in the high FFA and water contained feedstock, base catalysts could cause saponification which, lead to reduced final biodiesel yield. ${ }^{13}$ Thus, the acidic raw materials should be pretreated to minimize the FFA contents. ${ }^{\mathbf{1 4}}$ Comparing to base-catalysts, results also indicated that acidic materials have better yields in the presence of water or FFA. ${ }^{\mathbf{1 4}}$ Homogeneous acids such as $\mathrm{H}_{2} \mathrm{SO}_{4}, \mathrm{H}_{3} \mathrm{PO}_{4}$ and $\mathrm{HCl}$ solutions could corrode the vessel. ${ }^{5}$ In contrast, heterogeneous acid catalysts can overcome these drawbacks and be easily separated from the products. ${ }^{15}$ Recent developed heterogeneous catalysts such as the acid/base modified inorganic mixed oxides, amphoteric oxide, zeolites and cation-exchange resins have been employed in transesterification reactions. ${ }^{13}$ In general, the stronger acidic catalysts with porous structures and high surface areas lead to higher catalytic activity. For instance, by using a solid mixed-oxide superacid $\left(\mathrm{SO}_{4}{ }^{2-} / \mathrm{SnO}_{2}-\mathrm{SiO}_{2}\right)$, Man Kee Lam et al. achieved an optimum yield of $92.3 \%$ at reaction temperature $150{ }^{\circ} \mathrm{C}$, catalyst loading $3 \mathrm{wt} \%$, reaction time $3 \mathrm{~h}$, with a methanol-to-oil ratio of $15 .{ }^{16}$ Rui et al. ${ }^{17}$ have reported that $96.8 \%$ conversion for palmitic acid and $97.2 \%$ yield of fatty acid methyl ester (FAME) from transesterification reaction 
under the optimum reaction conditions as using $\mathrm{H}_{3} \mathrm{PW}_{12} \mathrm{O}_{40}$ / agarose.

Recent studies showed that the utilization of carbon based solid acid catalysts for biodiesel production processes is promising, as the carbon materials or their precursors are renewable and the feedstock for the acid catalysts preparation are of low-cost. ${ }^{18,19}$ Although the method to prepare sulfonated carbon catalyst is simple, it is challenging to obtain catalyst with high total acid density and to prevent the active site, such as $\mathrm{SO}_{3} \mathrm{H}$, leaching from the structure. ${ }^{18}$ Maneechakr et al. ${ }^{\mathbf{2 0}}$ synthesized a type of sulfonated carbon catalyst by hydrothermal carbonization of glucose. The cyclic structure precursor leads to a highly stable and active catalyst for transesterification process, affording a biodiesel conversion of $89.5 \%$ at $136{ }^{\circ} \mathrm{C}$. However, the high conversion is acquired at the expense of long reaction time of $\sim 16 \mathrm{~h}$. Therefore, developing highly efficient acid catalysts is essential for practical processes.

Carbon nanotubes (CNTs) have desirable structure and properties, such as high surface area, chemical stability, and low toxicity, to be employed as both catalysts and supports. ${ }^{21}$ By now, various supports such as covalent organic framework, mesoporous niobium oxide and other metal oxides (silica, alumina, zirconia, etc.) showed high efficiency. ${ }^{22-24}$ Compared with mineral supports, it can not be denied that the costs of carbon nanotube material preparation is higher than metal oxides. But CNTs can incorporate sulfonic groups effectively with polycyclic textural matrix and provide a surface with strong acidity, considerable solubility and stability. ${ }^{25}$ In addition, the hydrophobic property of carbon surface attracts the organic reactants and retards unfavorable reactions caused by the presence of $\mathrm{H}_{2} \mathrm{O} .{ }^{26}$ These characteristics have enabled tremendous opportunities for acidcatalyzed reactions. Oliveira et al. employed sulfonated carbon nanotubes as catalysts for the conversion of levulinic acid into ethyl levulinate and found that levulinc acid strongly adsorbs in the active sites of the sulfonated carbon nanotubes. ${ }^{27}$ The kinetic modeling studied by B. Likozar et al. ${ }^{28-30}$ advanced our understanding in detailed reaction kinetics of oil transesterification based on reaction scheme of individual triglyceride, diglyceride, monoglyceride, glycerol and other components of oil. Thus far, there are little comprehensive data reported in literatures on transesterification reaction by sulfonated CNTs in ethanol. Furthermore, the investigations about the mechanism of transesterification over solid acids are also limited.

Herein, we report our study and development on a highly efficient sulfonated multi-walled carbon nanotubes (S-MWCNT) catalyst for transesterification of trilaurin in ethanol solvent at temperatures of $130-170{ }^{\circ} \mathrm{C}$. The physical and structural properties of S-MWCNT are characterized by BET, FTIR, XPS and TEM. Furthermore, a kinetic model is proposed and the mechanism is discussed to provide an in-depth understanding into the transesterification reaction using S-MWCNTs catalysts.

\section{Experimental}

\subsection{Materials}

Concentrated $\mathrm{H}_{2} \mathrm{SO}_{4}(\mathrm{AR})$ and $\mathrm{HNO}_{3}(\mathrm{AR})$ were purchased from Chengdu Kelong Chemical Reagent Factory (China) and Tianjin
Fengchuan Reagent Technologies Co. Ltd. (China), respectively. Multi-walled carbon nanotubes (MWCNTs) (95\%) were purchased from Nanjing XFNANO Materials Tech Co. Ltd. The diameter and length are 20-30 $\mathrm{nm}$ and 0.5-2 $\mu \mathrm{m}$, respectively. Trilaurin (98\%) and ethanol (99.9\%) was purchased from Aladdin. And Tianjin Zhiyuan Chemical Reagents Co. Ltd. (China).

\subsection{Catalysts preparation}

The catalyst precursor was prepared by adding $1 \mathrm{~g}$ commercial MWCNTs to a beaker which contained $40 \mathrm{~mL} 1: 1$ concentrated $\mathrm{H}_{2} \mathrm{SO}_{4}$ and $\mathrm{HNO}_{3}$. The mixture was then placed under ultrasonication for $5 \mathrm{~h}$ to functionalize the nanotubes surface and remove surface impurities. After the sonication, the catalyst slurry was thoroughly washed with ultrapure water until $\mathrm{pH}$ reached 7 , and then dried at $70{ }^{\circ} \mathrm{C}$ for $12 \mathrm{~h}$. A total amount of $0.95 \mathrm{~g}$ purified MWCNTs (p-MWCNTs) was obtained after the purification process. The sulfonation of MWCNT was carried out using the following steps: $1 \mathrm{~g}$ p-MWCNTs were added to 5 $\mathrm{mL} \mathrm{H}_{2} \mathrm{SO}_{4}$ solution $\left(0.50 \mathrm{~mol} \mathrm{~L}^{-1}\right)$ with continuous stirring for $2 \mathrm{~h}$. The samples were then dried and stirred for $2 \mathrm{~h}$ in a water bath at $60-70{ }^{\circ} \mathrm{C}$ to produce the final catalysts.

\subsection{Characterization methods}

The specific surface area, pore size distributions, and pore volume were measured by Micromeritics Tristar 3020. The catalysts were degassed for $4 \mathrm{~h}$ at $300{ }^{\circ} \mathrm{C}$, and the $\mathrm{N}_{2}$ adsorptionisotherms of the catalysts were collected in liquid $\mathrm{N}_{2}\left(-196^{\circ} \mathrm{C}\right)$. The Barrett-Joyner-Hallender (BJH) method was used to calculate the pore size distribution by using the desorption branch. The Brunauer-Emmett-Teller (BET) method was used to calculate the specific surface area, with a relative pressure $(p)$ $p_{0}$ ) range of $0.1-0.3$. The morphology and structure of the catalyst were observed using an FEITecnai G2 F20 transmission electron microscope equipped with an energy-dispersive X-ray spectroscopy detector.

X-ray photoelectron spectra (XPS) were obtained with a ULVAC PHI 5000 Versa Probe-II instrument. The FT-IR spectra were measured on a BrukerTENSOR27 spectrophotometer (Germany). The range of detection wavelength is $400-4000 \mathrm{~cm}^{-1}$ and the number of scans and spectral resolution were 10 and 4 $\mathrm{cm}^{-1}$, respectively.

\subsection{Transesterification of trilaurin with ethanol}

In this experiment, trilaurin (0.0194 g), ethanol $(0.147 \mathrm{~mL})$, and S-MWCNTs $(0.0147 \mathrm{~g})$ were added into a $4 \mathrm{~mL}$ Swagelok reactor. The reactor was placed into a Techne fluidized sand bath (model SBL-2) after the temperature of sand bath reached the set point. ${ }^{31}$ The transesterification reactions were carried out at temperatures of $170,160,150,140$ and $130{ }^{\circ} \mathrm{C}$. After the reaction, the vessels were removed from sand bath and cooled to room temperature. The catalysts were recovered by washing with methanol at least four times to remove the residual of reactants. To ensure the residual reactants were completely removed, we put the catalyst in a container by pulling a vacuum 
on it at $150{ }^{\circ} \mathrm{C}$ for $15 \mathrm{~h}$ during the regeneration and reuse process.

A High Performance Liquid Chromatograph (HPLC) equipped with a AcclaimTM C18 column $(4.6 \mathrm{~mm}$ i.d. $\times 250 \mathrm{~mm}$ length) was used to analyze the products. ${ }^{31}$ The mobile phase contains $65 \%$ methanol and $35 \%$ acetonitrile at a flow rate of $0.6 \mathrm{~mL} \mathrm{~min}^{-1}$. The following conditions were used for the analysis: a detection temperature and time of $35^{\circ} \mathrm{C}$, and $30 \mathrm{~min}$ respectively, injection volume of $20 \mu \mathrm{L}$, and the UV detector wavelength of $210 \mathrm{~nm}$ were selected for the analysis.

\section{Results and discussion}

\subsection{Catalyst characterization}

Fig. 1 displays the $\mathrm{N}_{2}$ adsorption-desorption isotherm of $\mathrm{S}$ MWCNT. The type IV according to the BDDT (Brunauer S., Deming L. S., Deming W. E., Teller E.) classification shows the characteristic curve for mesoporous materials. S-MWCNTs exhibit a BET surface area of $198.9 \mathrm{~m}^{2} \mathrm{~g}^{-1}$ and pore sizes ranging from 5-35 $\mathrm{nm}$, with the majority of diameters of pores falling in the $10-15 \mathrm{~nm}$ region; the BET surface area of SMWCNTs is $198.9 \mathrm{~m}^{2} \mathrm{~g}^{-1}$. The MWCNTs possess a surface area of $228.1 \mathrm{~m}^{2} \mathrm{~g}^{-1}$ and pore size ranging from $20-45 \mathrm{~nm}$. The decrease in the surface area and pore size suggested that the acids groups were successfully attached onto MWCNTs and partially occupied pore space. As shown in Fig. 1, compared with S-MWCNTs, the BET surface area of the used catalyst was reduced by $\sim 20 \%$. As Pua et $a .^{32}$ illustrated in their study, the catalyst's surface area substantially decreased after sulfonation due to the collapse of pore structure. Compared with their findings, the slightly decrease in catalyst surface area observed in this study indicated that MWCNTs maintained sufficient stability against sulfonation-derived structural change/collapse. ${ }^{27}$

Fig. 2a shows the XPS spectra for the deconvoluted peaks for the element of C1s, O1s, and S2p on S-MWCNTs surface. The C1s spectrum can be deconvoluted into four peaks including $\mathrm{C}=\mathrm{C}$ at $284.13 \mathrm{eV}, \mathrm{C}-\mathrm{C}$ and $\mathrm{C}-\mathrm{H}$ at $284.59 \mathrm{eV}, \mathrm{C}=\mathrm{O}$ at $286.68 \mathrm{eV}, \mathrm{C}^{*}(\mathrm{O})$ $\mathrm{OC}$ at $288.23 \mathrm{eV}$ and $\mathrm{C} *(\mathrm{O}) \mathrm{OH}$ and $\mathrm{CSO}_{3} \mathrm{H}$ at $290.83 \mathrm{eV}$. There are four peaks associated with the $\mathrm{O} 1 \mathrm{~s}$ spectrum, centered at $531.25 \mathrm{eV}(\mathrm{S}=\mathrm{O}), 531.9 \mathrm{eV}(\mathrm{S}-\mathrm{OH}), 532.69 \mathrm{eV}(\mathrm{C}=\mathrm{O})$, and $533.44 \mathrm{eV}(\mathrm{C}-\mathrm{OH})$. The two peaks can be corresponded to S2p spectrum, including S2p3/2 at $168.83 \mathrm{eV}$ and S2p1/2 at $169.93 \mathrm{eV}$, which can be related to $\mathrm{SO}_{3} \mathrm{H}^{25,33}$ Additionally, the sulfonic acidity can be estimated by using the XPS elemental analysis. All the sulfur content exists in the form of sulfonic groups just as the FT-IR shows. ${ }^{25}$ The surface atomic concentrations of C1s, O1s, and S2p were calculated and are shown in Table 1. The results indicated that high $\mathrm{SO}_{3} \mathrm{H}$ density was obtained on S-MWCNT.

Fig. 3 shows the FT-IR spectra of the S-MWCNTs. The broad line centered at $3411 \mathrm{~cm}^{-1}$ is associated with $\mathrm{OH}$ stretching. ${ }^{34}$ Peaks at $2926 \mathrm{~cm}^{-1}$ and $2855 \mathrm{~cm}^{-1}$ correspond to the band of $\mathrm{CH}_{2} \cdot{ }^{34}$ The band at $1634 \mathrm{~cm}^{-1}$ is ascribed to the aromatic-like $\mathrm{C}=\mathrm{C}$ stretching mode of MWCNT graphic layers near the modified sites or carbonyl groups $\left(1626 \mathrm{~cm}^{-1}\right){ }^{34,35}$ Since the pretreatment of CNTs by using concentrated sulfuric acid and nitric acid introduced carboxylic acid, alcohols, and ketones, the $\mathrm{C}-\mathrm{O}$ stretching mode in alcohol species at $1114 \mathrm{~cm}^{-1}$ were

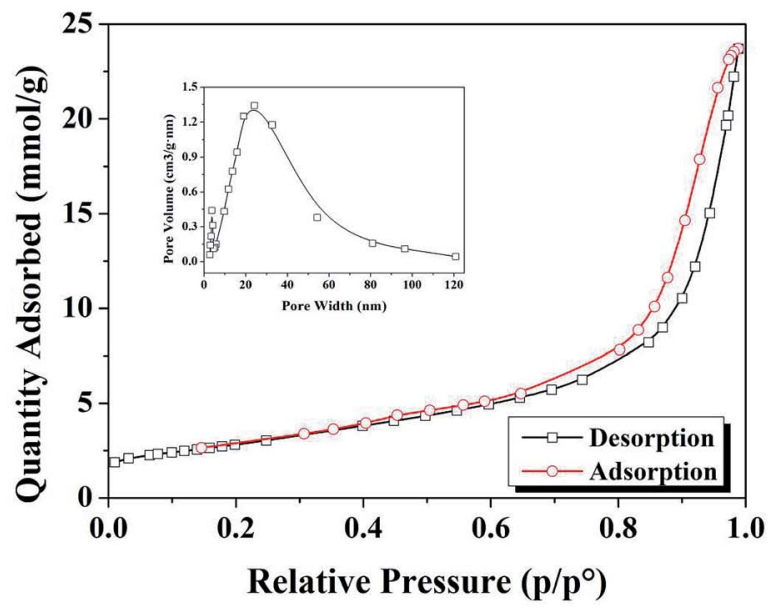

(a)

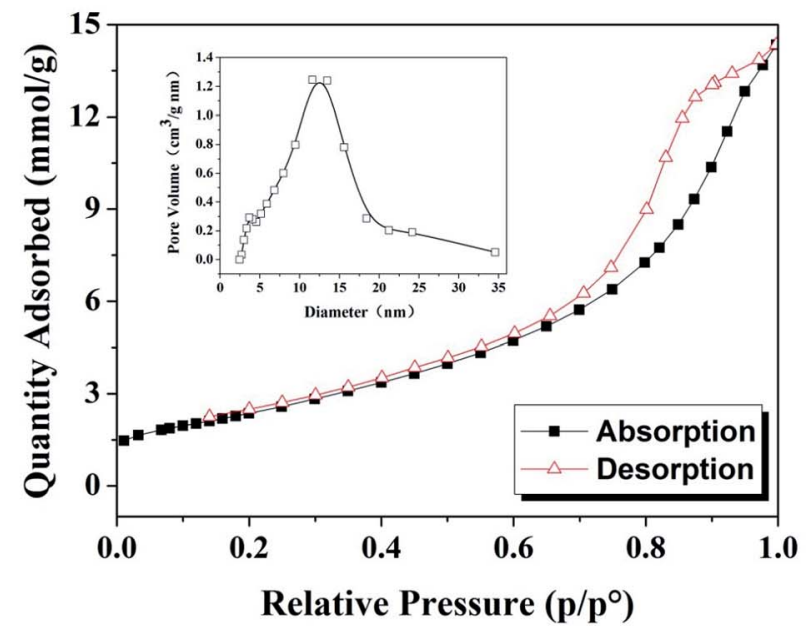

(b)

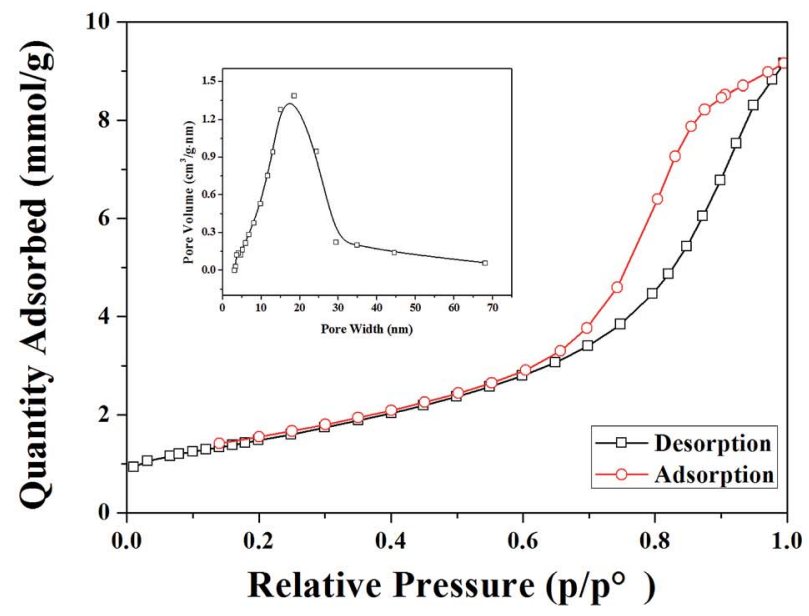

(c)

Fig. 1 The $\mathrm{N}_{2}$ adsorption-desorption isotherms and pore size distributions of the studied catalysts: (a) MWCNT, (b) new S-MWCNTs and (c) after the first use S-MWCNTs. 


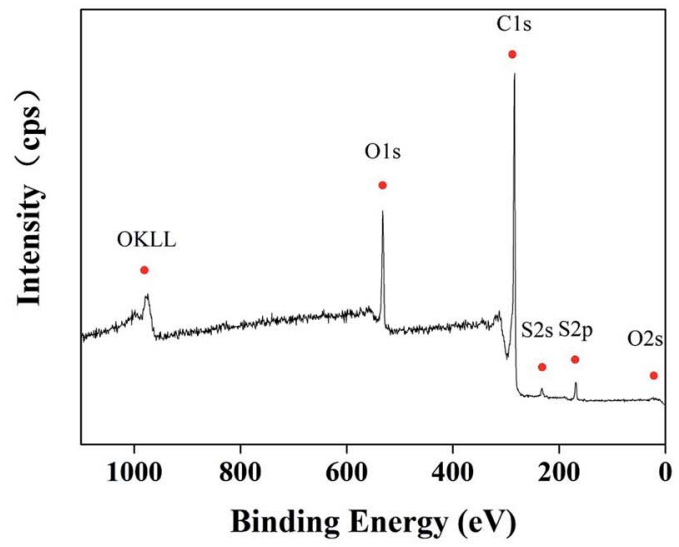

(a)

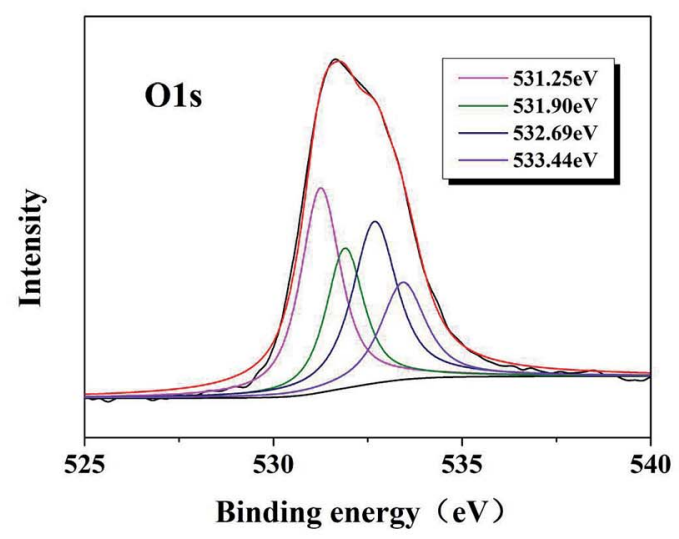

(c)

Fig. 2 XPS profiles of S-MWCNTs

Table 1 Surface atomic concentration (atomic\%) from XPS

\begin{tabular}{llll}
\hline Element & C1s & O1s & S2p \\
\hline Atomic\% & 84.71 & 13.68 & 1.62
\end{tabular}

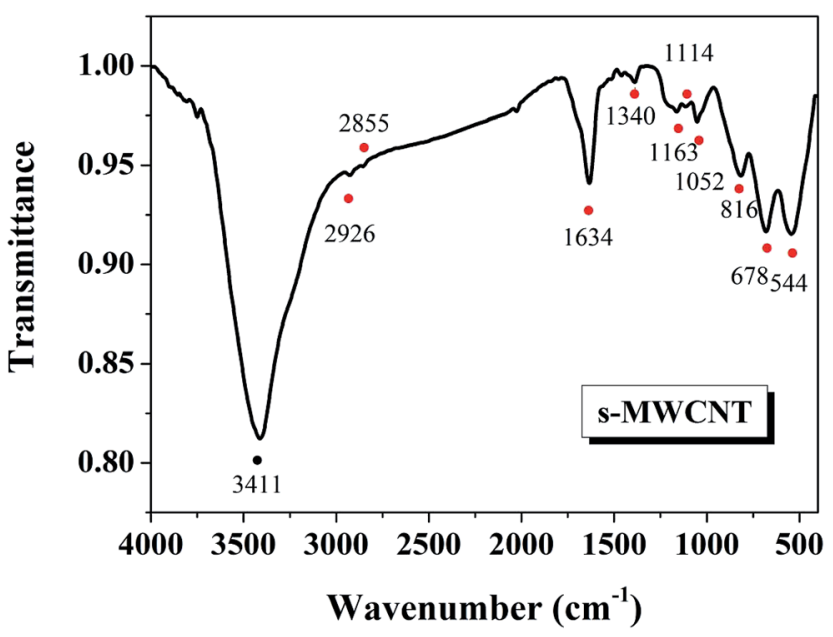

Fig. 3 FTIR spectra of S-MWCNTs.

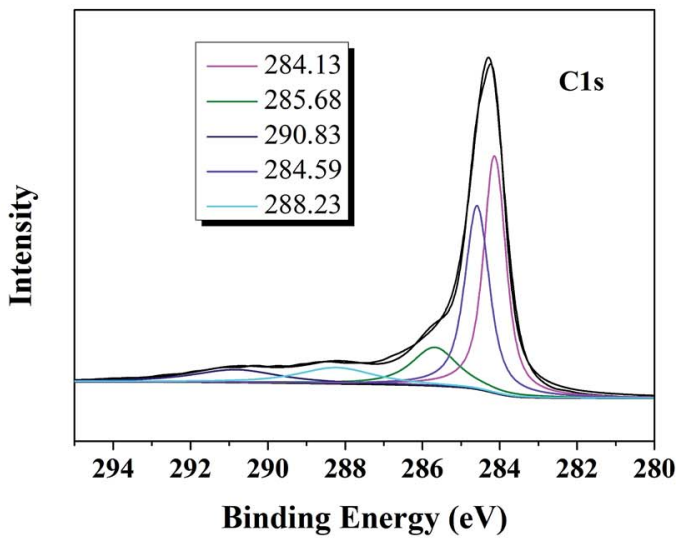

(b)

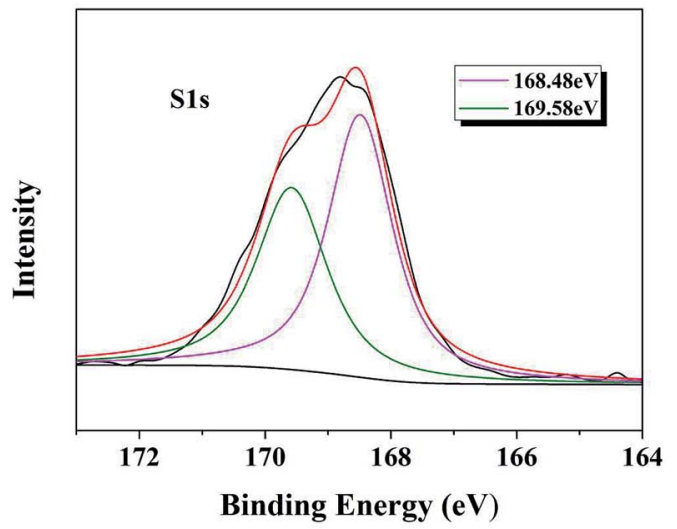

(d) also observed. ${ }^{33}$ The presence of the sulfonic acid group can be demonstrated by the bands at $544 \mathrm{~cm}^{-1}, 1340 \mathrm{~cm}^{-1}$ which corresponded to the symmetric, asymmetric $\mathrm{C}-\mathrm{S}, \mathrm{C}-\mathrm{SO}_{3}$, respectively. ${ }^{25,35}$ Two characteristic peaks at 1163 and $1052 \mathrm{~cm}^{-1}$ can be assigned to the $\mathrm{SO}_{3} \mathrm{H}$ groups asymmetric and symmetric vibrational absorption. ${ }^{33,36}$ The line at $678 \mathrm{~cm}^{-1}$ also confirms the presence of $\mathrm{S}=\mathrm{O}$ stretching mode for $-\mathrm{SO}_{3} \mathrm{H}$ group. ${ }^{25}$

Fig. 4 shows the TEM micrographs for the morphology and structure of MWCNTs and S-MWCNTs. As observed from Fig. 4a and $b$, the S-MWCNTs was highly dispersed following the sulfonation through ultrasonication. These micrographs indicated that the sulfonation did not induce significant collapse to the surface or the pore of the MWCNTs, consistent with the findings from a previous study. ${ }^{21}$ The diameters of the MWCNTs range between 20 and $30 \mathrm{~nm}$ as observed in Fig. 4a and d. The TEM of the reused catalyst (Fig. 4e) shows that the CNTs agglomerated and produced more defects, where the nanotubes suffered from significant bending and breakage. This observation is also consistent with BET measurements.

\subsection{Transesterification of trilaurin by S-MWCNTs}

S-MWCNTs were used as solid acid catalysts for transesterification of trilaurin in ethanol at temperatures of 130- 

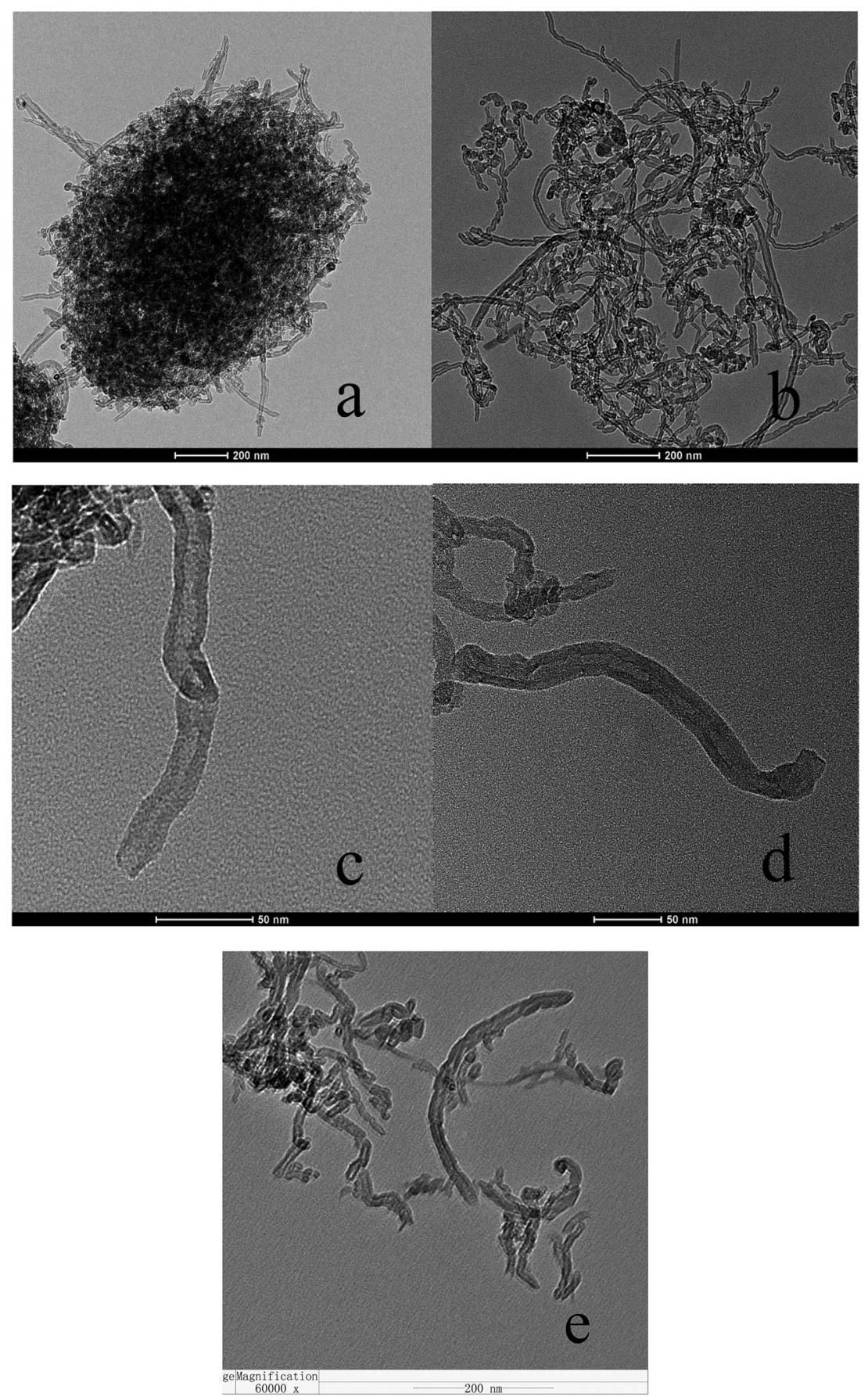

Fig. 4 TEM images of MWCNTs ( $a$ and $c$ ), new S-MWCNTs ( $b$ and $d$ ) and after the first use S-MWCNTs (e).

$170{ }^{\circ} \mathrm{C}$ with a $3.7 \mathrm{wt} \%$ catalyst loading and a $1: 20$ ethanol to trilaurin mass ratio. As shown in Fig. 5, triglycerides transesterification using S-MWCNTs achieved a total biodiesel yield of $78 \%$ at $150{ }^{\circ} \mathrm{C}$ with a dwell time of $30 \mathrm{~min}$, comparable to the performance using $0.5 \mathrm{~mol} \mathrm{~L}^{-1}$ dilute sulfuric acid. The results indicated that the sulfonation has sufficiently functionalized and modified the MWCNTs to perform as effectively as $\mathrm{H}_{2} \mathrm{SO}_{4}$ based homogeneous catalyst.

Fig. 6 shows that the reaction achieved a yield of $97.8 \%$ of ethyl ester at $150{ }^{\circ} \mathrm{C}$ and a yield of $68.8 \%$ at $130{ }^{\circ} \mathrm{C}$ in only $1 \mathrm{~h}$.
Maneechakr et $a .^{20}$ reported the highest biodiesel yield of $89.5 \%$ over sulfonated carbon catalyst at $136{ }^{\circ} \mathrm{C}$ and $16.1 \mathrm{~h}$ with catalyst loading of $12.3 \mathrm{wt} \%$. Our results showed that S-MWCNT have superior catalytic performance for transesterification of trilaurin in ethanol system. Even comparing with metal oxide catalyst $\left(\mathrm{SO}_{4}{ }^{2-} / \mathrm{SnO}_{2}-\mathrm{SiO}_{2}\right)$, which was reported to exhibit an optimum yield of $92.3 \%$ at $150{ }^{\circ} \mathrm{C}$, catalyst loading of $3 \mathrm{wt} \%$, with methanol-to-oil ratio of 15 and reaction time of $3 \mathrm{~h},{ }^{16} \mathrm{~S}$ MWCNTs used in our study outperformed these metal oxide based catalysts in $1 \mathrm{~h}$. The first reused catalyst showed similar 


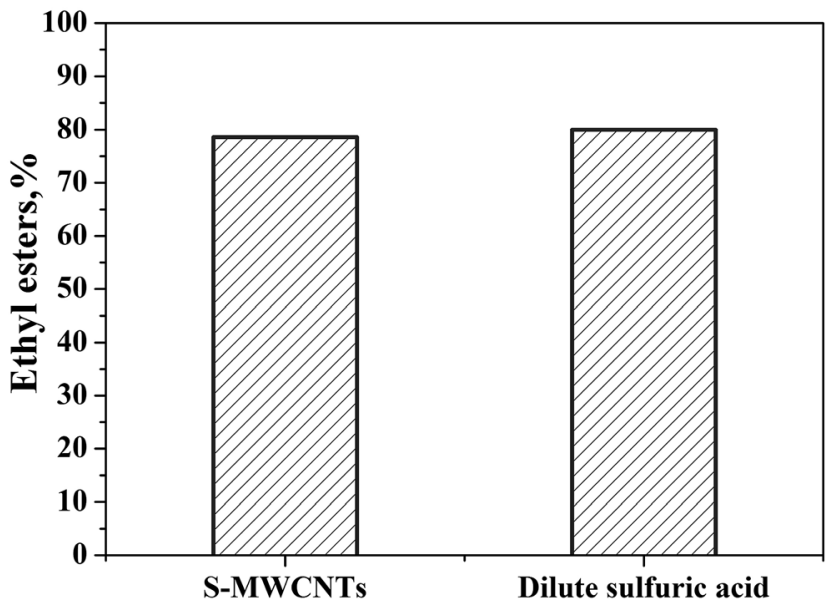

Fig. 5 Ethyl ester yield using S-MWCNTs and $0.5 \mathrm{~mol} \mathrm{~L}^{-1}$ sulfuric acid as catalysts at the same condition.

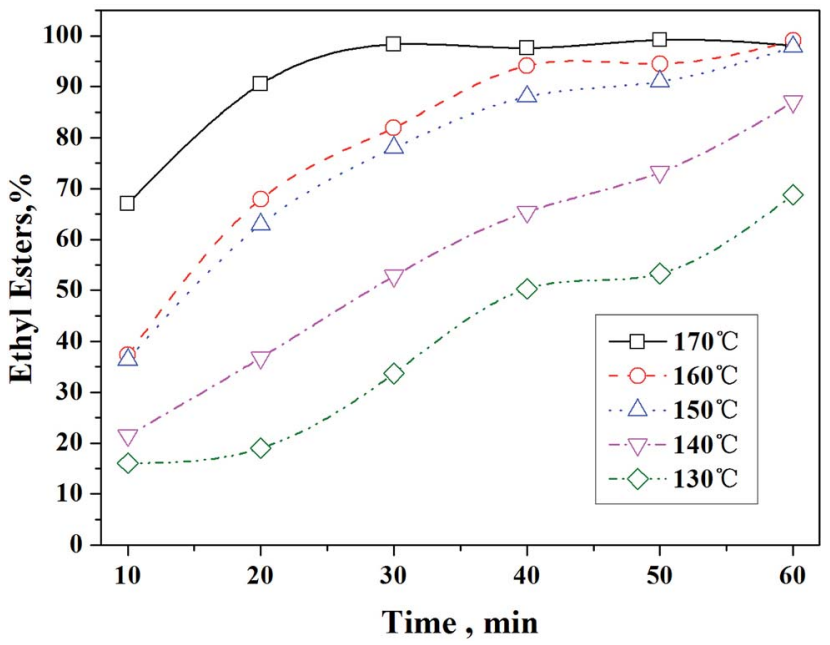

Fig. 6 Ethyl ester yield as a function of reaction time on S-MWCNTs.

initial activity for the transesterification of trilaurin at $150{ }^{\circ} \mathrm{C}$ but lost $\sim 13 \%$ of its activity after $1 \mathrm{~h}$ of reaction. The main causes of catalyst deactivation were the loss of catalyst surface area and agglomeration of CNTs. These results indicated that SMWCNTs are highly-effective heterogeneous acid catalysts for transesterification.

The kinetics of the trilaurin transesterification to ethyl esters has been extensively studied in the other work. ${ }^{31}$ In this transesterification process with ethanol, the products include three species: ethyl esters (EE), unethyl esterified compounds (UEE) and glycerin (GL). The uEE contains monolaurin, dilaurin, trilaurin. A simple mathematical model, which neglects the intermediate reactions of diglycerides and monoglycerides was proposed by Kusdiana and Saka, ${ }^{37}$ in this model, methanol concentration was considered to be constant, and the reaction were assumed to be first order. This model quantified the effect of temperature and determined the apparent activation energy.

As shown in Fig. $7,{ }^{38}$ we simplified the reaction scheme of the transesterification process to one-step reaction. The consumption

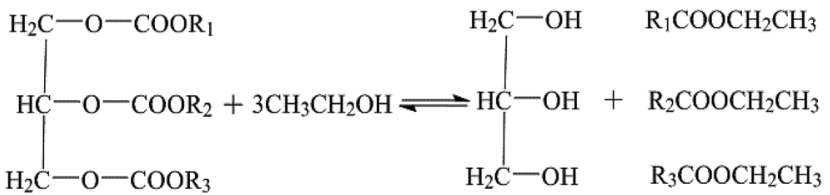

Fig. 7 The reaction scheme for simplified one-step transesterification of triglycerides by ethanol.

of ethanol was assumed to be negligible for this model as ethanol was fed substantially in excess. The kinetics of uEE can be described by eqn (1):

$$
\frac{\mathrm{d} C_{\mathrm{uEE}}}{\mathrm{d} t}=-k C_{\mathrm{uEE}}{ }^{n} .
$$

where $C_{\mathrm{uEE}}$ and $k$ denote concentration of unethyl esterified compounds and the reaction rate, respectively.

As shown in Fig. 8, Berkeley Madonna simulator was used to fit experimental data consisting of UEE concentrations as a function of time to the model as described in eqn (1) and the reaction order of $n=1$ is obtained.

The rate constants of $k_{1}, k_{2}, k_{3}, k_{4}$ and $k_{5}$ can then be computed at temperatures $130-170{ }^{\circ} \mathrm{C}$, with $10{ }^{\circ} \mathrm{C}$ increment. Table 2 displays the rate constants at different temperature, as well as other determinant reaction conditions. According to the Arrhenius equation (eqn (2)), the increase of temperature leads to the increase of rate constants. The corresponding Arrhenius plot is illustrated in Fig. 9 with $R^{2}=0.987$, validating the feasibility to use the pseudo-first-order reaction model to obtain the kinetic information on triglycerides transesterification.

$$
\ln k=\ln A-\frac{E_{\mathrm{a}}}{R T}
$$

where $A$ is pre-exponential factor and $E_{\mathrm{a}}$ is activation energy, respectively.

Table 2 also shows the Arrhenius parameters calculated from the reaction model; activation energy and pre-exponential factor are computed to be $72 \pm 4 \mathrm{~kJ} \mathrm{~mol}^{-1}$ and $2.4 \times 10^{7}$, respectively.

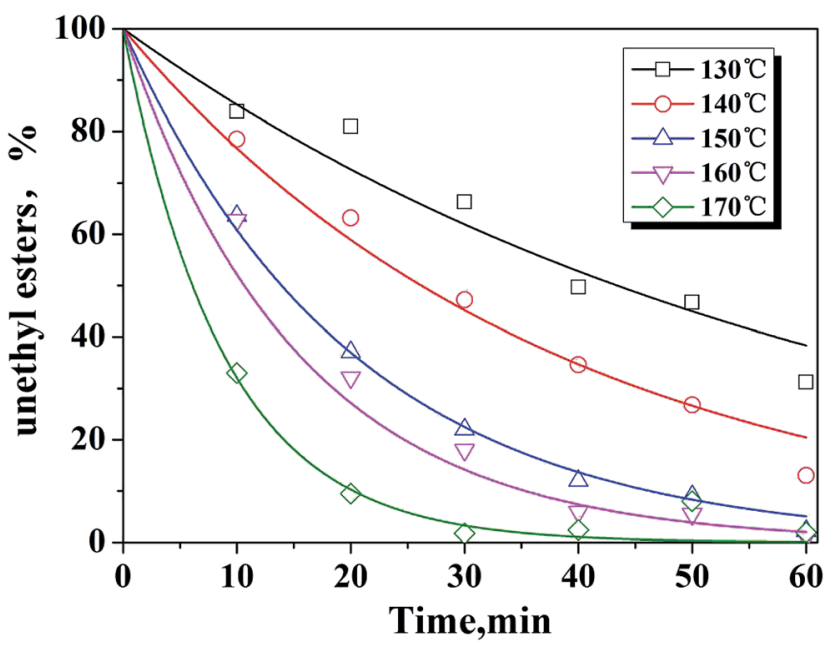

Fig. 8 Simulated vs. experimental results for uEE (unethyl esterified compounds) in ethanol using S-MWCNTs as the catalyst. 


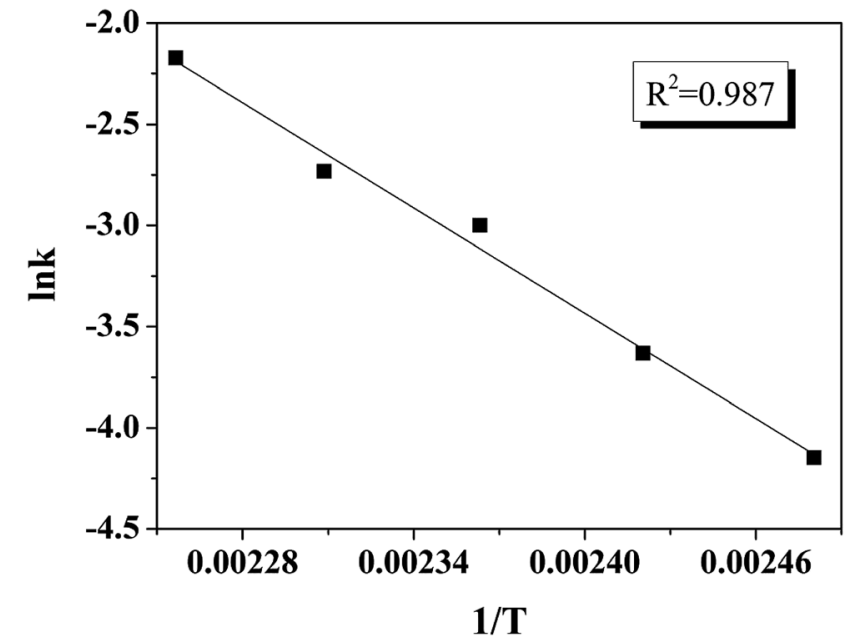

Fig. 9 The Arrhenius plot of the reaction rate constants at temperatures of $130-170{ }^{\circ} \mathrm{C}$.

Table 2 Rate constants, reaction order $(n)$ and Arrhenius parameters

\begin{tabular}{lllll}
\hline Temperature $\left({ }^{\circ} \mathrm{C}\right)$ & $k\left(\mathrm{~min}^{-1}\right)$ & $n$ & $E_{\mathrm{a}}\left(\mathrm{kJ} \mathrm{mol}^{-1}\right)$ & $\ln A\left(\mathrm{~min}^{-1}\right)$ \\
\hline 130 & 0.01580 & 1 & $72.1 \pm 4.1$ & $17.38 \pm 1.16$ \\
140 & 0.02645 & 1 & & \\
150 & 0.04980 & 1 & & \\
160 & 0.0650 & 1 & & \\
170 & 0.1139 & 1 & &
\end{tabular}

The rate constant of $0.1 \mathrm{~min}^{-1}$ was obtained even at $170{ }^{\circ} \mathrm{C}$. However, according to the research done by Silva et al. ${ }^{39}$ similar rate constant can only be achieved at $350{ }^{\circ} \mathrm{C}$ for soybean oil transesterification. This comparison clearly indicates that the SMWCNTs exhibit superior performance compared to other high-performing catalysts in the literature.

\subsection{Mechanism}

We proposed the following mechanism for the transesterification of triglycerides by S-MWCNTs. Triglyceride molecule was first adsorbed on S-MWCNTs surface; the adsorption site was plausibly provided by $\mathrm{SO}_{3} \mathrm{H}$ groups through interaction between the acid sites/protons and the oxygen atom in the ester linkage. It is anticipated that $\mathrm{SO}_{3} \mathrm{H}$ groups received a pair of electrons from the oxygen atom in $\mathrm{C}-\mathrm{O}-\mathrm{C}$. The attack to the oxygen atom likely weakened the $\mathrm{C}-\mathrm{O}-\mathrm{C}$ bond, which led to the production of the carbonyl carbon OR1.

The adsorption of ethanol also undergoes a similar process. The sulfate ions enhance the nucleophilicity of ethanol to donate protons $\left(\mathrm{H}^{+}\right)$. The attack to the sulfate ions on $\mathrm{C}-\mathrm{O}-\mathrm{C}$ weakens the bond strength of the carbonyl carbon -OR. Nucleophilic ethanol then attacks the carbonyl carbon to produce $\mathrm{CH}_{3} \mathrm{CH}_{2} \mathrm{COOR}$. Finally, the protons $\left(\mathrm{H}^{+}\right)$released from ethanol replace $\mathrm{SO}_{3} \mathrm{H}$ in $\mathrm{R}-\mathrm{OSO}_{3} \mathrm{H}$ to produce monoglycerides, diglycerides or glycerine. The scheme for the mechanism is illustrated in Fig. 10.

\section{Conclusions}

Sulfonated MWCNTs shows superior catalytic activity for transesterification of triglycerides in ethanol due to its high acid site, high surface area, suitable interval porosity size, and high dispersion. The structure of sulfonated MWCNTs is sufficiently stable to retain its catalytic performance during the reaction process, providing economical and environmental benefits for
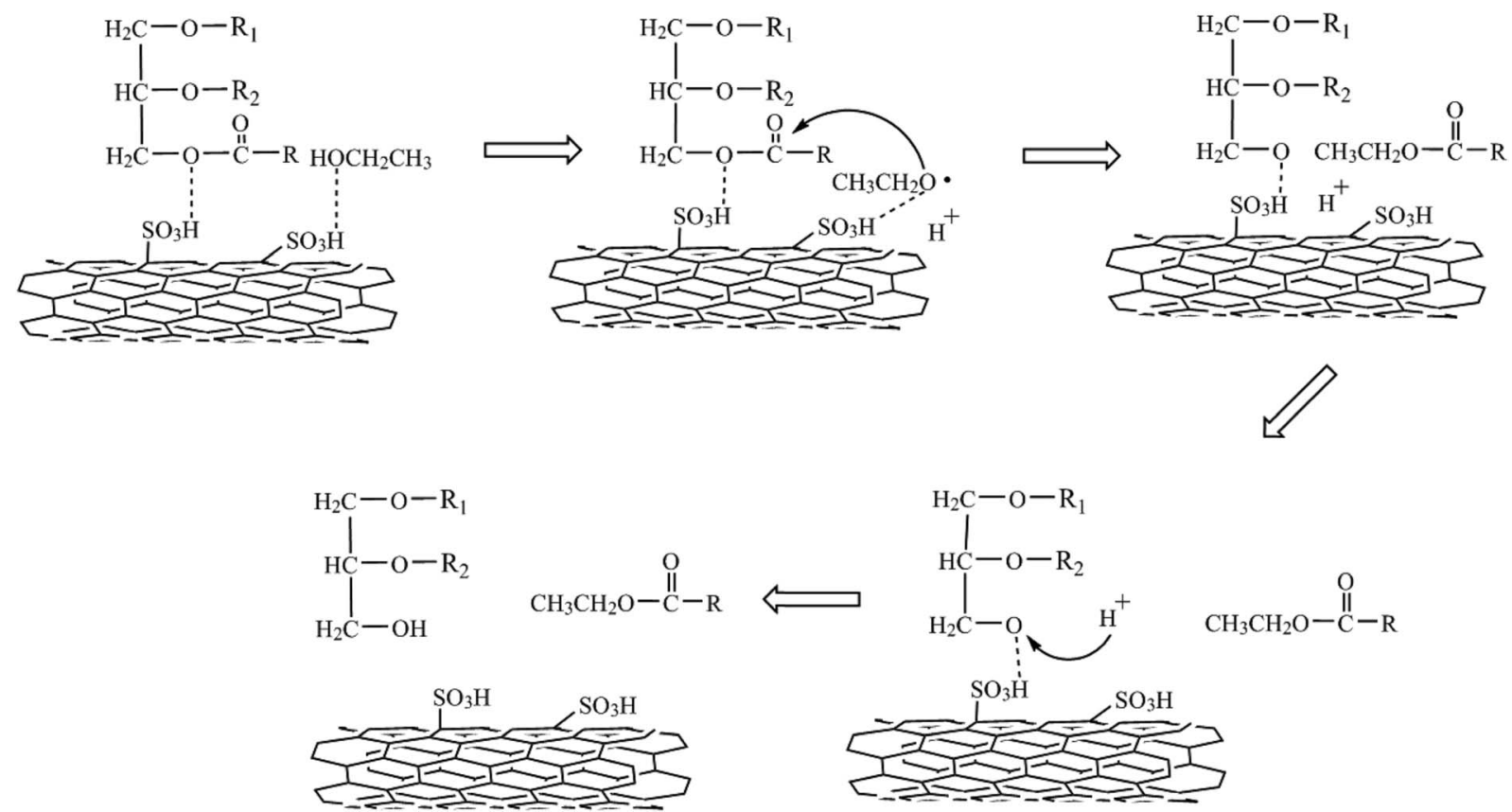

Fig. 10 The proposed mechanism for the transesterification reaction in ethanol on S-MWCNTs. 
catalyst regeneration and reuse. Compared with mineral acids, there are also some challenges in the costs of carbon nanotube material preparation and their subsequent functionalisation. And these kind of catalysts are difficult to recycle when operating in batch reaction mode. We used S-MWCNTs in ethanol at different temperatures for transesterification of trilaurin, affording an overall conversion of $\sim 90 \%$ in $20 \mathrm{~min}$ at $170{ }^{\circ} \mathrm{C}$ with a $3.7 \mathrm{wt} \%$ catalyst loading and a $1: 20$ ethanol to trilaurin mass ratio. Up to $70 \%$ of ethyl ester yield was achieved at $130{ }^{\circ} \mathrm{C}$ and $1 \mathrm{~h}$ of reaction. A kinetic study on unethyl esterified (UEE) compounds showed a pseudo-first-order kinetics with the Arrhenius parameters for the pre-exponential factor and activation energy to be $2.4 \times 10^{7}$ and $72 \pm 4 \mathrm{~kJ} \mathrm{~mol}^{-1}$, respectively. We also proposed the mechanism for the reaction, where triglycerides and ethanol were adsorbed on $\mathrm{SO}_{3} \mathrm{H}$ groups through interaction between the acid sites and the oxygen atom; then nucleophilic ethanol attacked the carbonyl carbon to produce $\mathrm{CH}_{3} \mathrm{CH}_{2} \mathrm{COOR}$. The findings of this work has shed lights on the use of S-MWNCTs as effective heterogeneous acid catalysts for transesterification reaction and eventually provide useful information on designing metal-free, low-cost solid acid catalyst for biodiesel production.

\section{Acknowledgements}

This work is supported by the National Natural Science Foundation of China (21307049 and U1137603), the High Technology Talent Introduction Project of Yunnan in China (2010CI110) and Collaborative Innovation Center of Western Typical Industry Environmental Pollution Control.

\section{References}

1 L. Meher, D. Vidyasagar and S. Naik, Technical aspects of biodiesel production by transesterification-a review, Renewable Sustainable Energy Rev., 2006, 10(3), 248-268.

2 F. Ma and M. A. Hanna, Biodiesel production: a review, Bioresour. Technol., 1999, 70(1), 1-15.

3 O. Özener, L. Yüksek, A. T. Ergenç and M. Özkan, Effects of soybean biodiesel on a DI diesel engine performance, emission and combustion characteristics, Fuel, 2014, 115(1), 875-883.

4 E. Lotero, Y. Liu, D. E. Lopez, K. Suwannakarn, D. A. Bruce and J. G. Goodwin, Synthesis of Biodiesel via Acid Catalysis, Ind. Eng. Chem. Res., 2005, 44(14), 5353-5363.

5 A. Talebian-Kiakalaieh, N. A. S. Amin and H. Mazaheri, A review on novel processes of biodiesel production from waste cooking oil, Appl. Energy, 2013, 104, 683-710.

6 W. Y. Lou, M. H. Zong and Z. Q. Duan, Efficient production of biodiesel from high free fatty acid-containing waste oils using various carbohydrate-derived solid acid catalysts, Bioresour. Technol., 2008, 99(18), 8752-8758.

7 A. M. Dehkordi and M. Ghasemi, Transesterification of waste cooking oil to biodiesel using $\mathrm{Ca}$ and $\mathrm{Zr}$ mixed oxides as heterogeneous base catalysts, Fuel Process. Technol., 2012, 97(2), 45-51.
8 A. E. Ghaly, D. Dave, M. S. Brooks and S. Budge, Production of biodiesel by enzymatic transesterification: review, Am. J. Biochem. Biotechnol., 2010, 6(2), 54-76.

9 A. Guldhe, B. Singh, I. Rawat and F. Bux, Synthesis of biodiesel from Scenedesmus sp. by microwave and ultrasound assisted in situ transesterification using tungstated zirconia as a solid acid catalyst, Chem. Eng. Res. Des., 2014, 92(8), 935-949.

10 J. K. Rodríguez-Guerrero, M. F. Rubens and P. T. V. Rosa, Production of biodiesel from castor oil using sub and supercritical ethanol: Effect of sodium hydroxide on the ethyl ester production, J. Supercrit. Fluids, 2013, 83(11), 124-132.

11 A. S. Badday, A. Z. Abdullah and L. Keatteong, Optimization of biodiesel production process from Jatropha oil using supported heteropolyacid catalyst and assisted by ultrasonic energy, Renewable Energy, 2013, 50(3), 427-432.

12 I. M. Atadashi, M. K. Aroua, A. R. A. Aziz and N. M. N. Sulaiman, The effects of catalysts in biodiesel production: A review, J. Ind. Eng. Chem., 2013, 19(1), 14-26.

13 M. E. Borges and L. Diaz, ChemInform Abstract: Recent Developments on Heterogeneous Catalysts for Biodiesel Production by Oil Esterification and Transesterification Reactions, ChemInform, 2013, 16(11), 2839-2849.

14 B. Freedman, E. H. Pryde and T. L. Mounts, Variables affecting the yields of fatty esters from transesterified vegetable oils, J. Am. Oil Chem. Soc., 1984, 61(10), 1638-1643.

15 P. A. Alaba, Y. M. Sani and W. M. Ashri Wan Daud, Efficient biodiesel production via solid superacid catalysis: a critical review on recent breakthrough, $R S C A d v .$, 2016, 6(82), 78351-78368.

16 K. L. Man, K. T. Lee and A. R. Mohamed, Sulfated tin oxide as solid superacid catalyst for transesterification of waste cooking oil: An optimization study, Appl. Catal., B, 2009, 93(1-2), 134-139.

17 R. Hou, D. Zhang, X. Duan, X. Wang, S. Wang and Z. Sun, Fabrication of H3PW12O40/agarose membrane for catalytic production of biodiesel through esterification and transesterification, RSC Adv., 2016, 6(85), 81794-81801.

18 L. J. Konwar, J. Boro and D. Deka, Review on latest developments in biodiesel production using carbon-based catalysts, Renewable Sustainable Energy Rev., 2014, 29(7), 546-564.

19 L. Cai, D. Meng, S. Zhan, X. Yang, T. Liu, H. Pu and X. Tao, $\mathrm{SO} 3 \mathrm{H}$ and $\mathrm{NH} 2+$ functional carbon-based solid acid catalyzed transesterification and biodiesel production, $R S C$ Adv., 2015, 5(88), 72146-72149.

20 P. Maneechakr, J. Samerjit, S. Uppakarnrod and S. Karnjanakom, Experimental design and kinetic study of ultrasonic assisted transesterification of waste cooking oil over sulfonated carbon catalyst derived from cyclodextrin, J. Ind. Eng. Chem., 2015, 32, 128-136.

21 F. Peng, L. Zhang, H. Wang, P. Lv and H. Yu, Sulfonated carbon nanotubes as a strong protonic acid catalyst, Carbon, 2005, 43(11), 2405-2408.

22 Y. Peng, Z. Hu, Y. Gao, D. Yuan, Z. Kang, Y. Qian, N. Yan and D. Zhao, Synthesis of a Sulfonated Two-Dimensional 
Covalent Organic Framework as an Efficient Solid Acid Catalyst for Biobased Chemical Conversion, ChemSusChem, 2015, 8(19), 3208-3212.

23 E. L. S. Ngee, Y. Gao, X. Chen, T. M. Lee, Z. Hu, D. Zhao and N. Yan, Sulfated Mesoporous Niobium Oxide Catalyzed 5Hydroxymethylfurfural Formation from Sugars, Ind. Eng. Chem. Res., 2014, 53(37), 14225-14233.

24 K. Saravanan, B. Tyagi and H. C. Bajaj, Sulfated zirconia: an efficient solid acid catalyst for esterification of myristic acid with short chain alcohols, Catal. Sci. Technol., 2012, 2(12), 2512.

25 H. Yu, Y. Jin, Z. Li, F. Peng and H. Wang, Synthesis and characterization of sulfonated single-walled carbon nanotubes and their performance as solid acid catalyst, $J$. Solid State Chem., 2008, 181(3), 432-438.

26 C. Poonjarernsilp, N. Sano and H. Tamon, Hydrothermally sulfonated single-walled carbon nanohorns for use as solid catalysts in biodiesel production by esterification of palmitic acid, Appl. Catal., B, 2014, 147(8), 726-732.

27 B. L. Oliveira and V. Teixeira da Silva, Sulfonated carbon nanotubes as catalysts for the conversion of levulinic acid into ethyl levulinate, Catal. Today, 2014, 234, 257-263.

28 B. Likozar and J. Levec, Effect of process conditions on equilibrium, reaction kinetics and mass transfer for triglyceride transesterification to biodiesel: experimental and modeling based on fatty acid composition, Fuel Process. Technol., 2014, 122, 30-41.

29 B. Likozar and J. Levec, Transesterification of canola, palm, peanut, soybean and sunflower oil with methanol, ethanol, isopropanol, butanol and tert-butanol to biodiesel: Modelling of chemical equilibrium, reaction kinetics and mass transfer based on fatty acid composition, Appl. Energy, 2014, 123, 108-120.

30 B. Likozar, A. Pohar and J. Levec, Transesterification of oil to biodiesel in a continuous tubular reactor with static mixers: Modelling reaction kinetics, mass transfer, scale-up and optimization considering fatty acid composition, Fuel Process. Technol., 2016, 142, 326-336.
31 Q. Q. Guan, S. Hua, L. Jing, J. J. Gu, B. Li, R. R. Miao, Q. L. Chen and N. Ping, Biodiesel from transesterification at low temperature by $\mathrm{AlCl} 3$ catalysis in ethanol and carbon dioxide as cosolvent: process, mechanism and application, Appl. Energy, 2016, 164, 380-386.

32 F. L. Pua, Z. Fang, S. Zakaria, F. Guo and C. H. Chia, Direct production of biodiesel from high-acid value Jatropha oil with solid acid catalyst derived from lignin, Biotechnol. Biofuels, 2012, 4(1), 66.

33 Y. Wei, X. Ling, L. Zou, D. Lai, H. Lu and Y. Xu, A facile approach toward preparation of sulfonated multi-walled carbon nanotubes and their dispersibility in various solvents, Colloids Surf., A, 2015, 482, 507-513.

34 F. Avilés, J. V. Cauich-Rodríguez, L. Moo-Tah, A. May-Pat and R. Vargas-Coronado, Evaluation of mild acid oxidation treatments for MWCNT functionalization, Carbon, 2009, 47(13), 2970-2975.

35 K. Jiang, A. Eitan, L. S. Schadler, P. M. Ajayan, R. W. Siegel, N. Grobert, M. Mayne, M. Reyes-Reyes, H. Terrones and M. Terrones, Selective Attachment of Gold Nanoparticles to Nitrogen-Doped Carbon Nanotubes, Nano Lett., 2003, 3(3), 275-277.

36 Y. Wei, X. Ling, L. Zou, D. Lai, H. Lu and Y. Xu, A facile approach towards preparation of sulfonated multi-walled carbon nanotubes and their dispersibility in various solvents, Colloids Surf., A, 2015, 482, 507-513.

37 G. Santori, G. D. Nicola, M. Moglie and F. Polonara, A review analyzing the industrial biodiesel production practice starting from vegetable oil refining, Appl. Energy, 2012, 92(4), 109-132.

38 G. F. Silva, F. L. Camargo and A. L. O. Ferreira, Application of response surface methodology for optimization of biodiesel production by transesterification of soybean oil with ethanol, Fuel Process. Technol., 2011, 92(3), 407-413.

39 C. Silva, T. A. Weschenfelder, S. Rovani, F. C. Corazza, M. L. Corazza, C. a. Dariva and J. Vladimir Oliveira, Continuous Production of Fatty Acid Ethyl Esters from Soybean Oil in Compressed Ethanol, Ind. Eng. Chem. Res., 2007, 46(16), 5304-5309. 